\title{
Una inscripción latina relativa a la fundación de Olite (Navarra)*
}

\section{A Latin inscription related to the foundation of Olite (Navarre)}

\author{
Javier Velaza** \\ Departamento de Filología Latina. Universidad de Barcelona
}

\begin{abstract}
RESUMEN
Editamos en este trabajo una nueva inscripción latina hallada en Sansomain (NA), que hace referencia a la fundación de Ologite por parte del rey godo Suintila.
\end{abstract}

\section{SUMMARY}

In this paper we edit a new Latin inscription found in Sansomain (NA), which refers to the foundation of Ologite by the Goth king Suintila.

PALABRAS CLAVE: Inscripción latina, Olite, Suintila, Isidoro de Sevilla.

KEYWORDS: Latin inscription, Olite, Suintila, Isidorus of Sevilla.

\section{LA INSCRIPCIÓN}

Según las informaciones que se nos han facilitado, la pieza de la que daremos cuenta en este trabajo fue encontrada a finales de los años setenta por Juan Ciriza, agricultor de Sansomain, entre las ruinas de lo que pudo ser una ermita en el término de

\footnotetext{
* Quiero expresar mi gratitud a todos los que me han facilitado la publicación de esta pieza: a Javier Corcín, que me informó de su existencia, me invitó a estudiarla y me brindó, una vez más, su generosa hospitalidad en Olite; a la familia Pamias Virto, en cuya casa de Sansomain se conservaba, y que con loable altruismo la ha donado al Ayuntamiento de Olite; y a la Asociación Astrolabio Románico, cuyo protagonismo en el descubrimiento de la piedra ha sido fundamental. Y también a mis colegas Helena Gimeno, José Luis Ramírez Sádaba e Isabel Velázquez, cuyas atinadas sugerencias han enriquecido mucho este trabajo. La responsabilidad última de lo que aquí se dice corresponde, por supuesto, a quien esto firma.

** Este trabajo se inscribe en el Proyecto FFI2011-25113 y en el Grup de Recerca Consolidat LITTERA (2009 SGR 1254).
}

Ariamain (Sansomain) (Fig. 1). De allí fue trasladada a la casa de la familia Pamias-Virto, en Sansomain, donde permaneció hasta 2010, cuando Enrique Pamias la mostró a Eduardo Bayona, miembro de la Asociación Astrolabio Románico, quien llevaba a cabo el estudio de la iglesia de Sansomain. Fueron los miembros de la citada asociación quienes advirtieron a los propietarios de la posible importancia de la pieza y, al mismo tiempo, comunicaron su existencia al Ayuntamiento de Olite y a la Asociación El Chapitel. El 8 de enero de 2011 se llevó a cabo el acto oficial de donación al Ayuntamiento. ${ }^{1}$

La pieza en cuestión es un bloque de forma paralelepipédica de piedra arenisca local (Fig. 2) de $38 \times$ $61 \times 48 \mathrm{~cm}$, ligeramente irregular en su cara superior $\mathrm{y}$ con diferentes golpes y desconchados en las caras laterales y anterior. Todas las caras han sido trabajadas y desbastadas a buril. La cara anterior, que contiene la inscripción, debió de presentar un campo epigráfico notablemente rebajado, de cuyo reborde solo quedan restos en la parte inferior derecha. Esta cara ha sufrido diversas pérdidas de material en sus bordes y desconchados en los ángulos superior izquierdo, superior derecho e inferior izquierdo, con grados diferentes de afectación al texto. En todo caso, es indudable que tales daños fueron producidos en época antigua, porque las superficies desconchadas han sufrido después una evidente erosión y están cubiertas por concreciones y una capa de líquenes que sin duda delatan una prolongada exposición a la humedad ambiental.

\footnotetext{
${ }^{1}$ En el momento de redactar estas páginas el Ayuntamiento de Olite no ha decidido todavía la ubicación final de la pieza.
} 


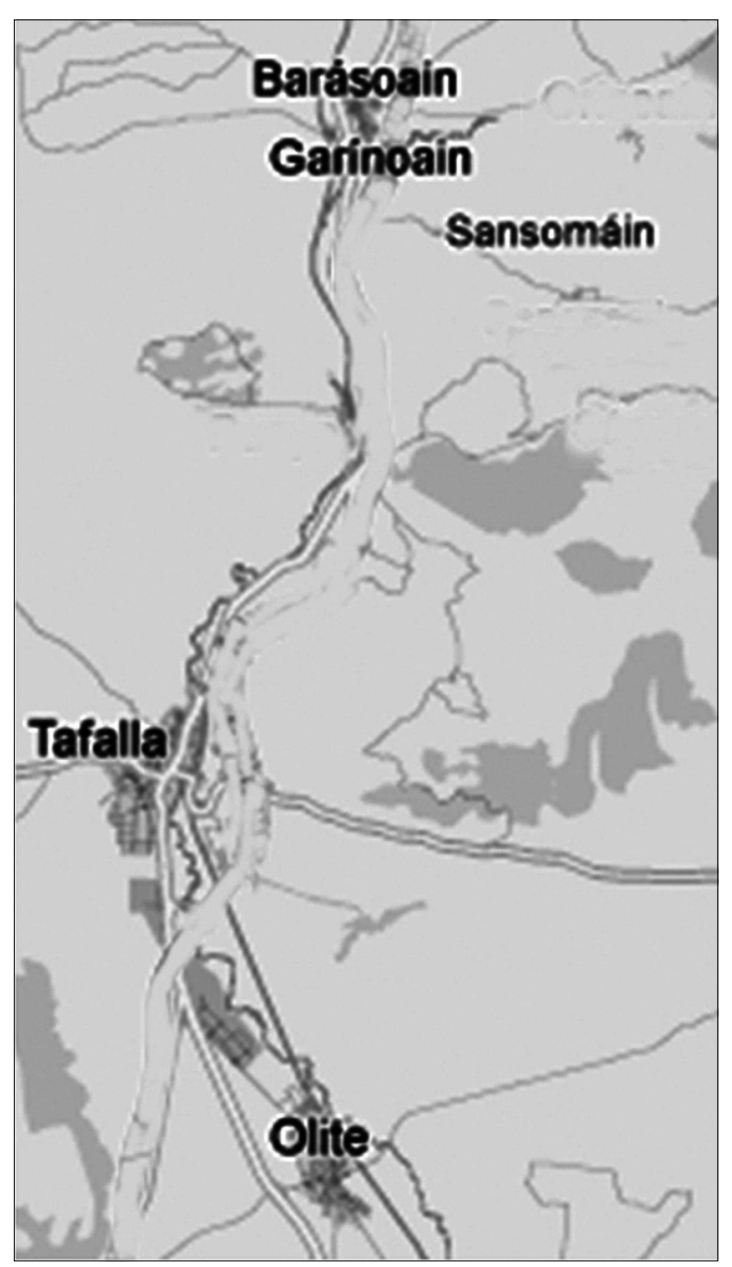

Figura.1 Mapa con la localización de Sansomain y Olite.

El texto de la inscripción ocupa la cara anterior y ha sido grabado en tres líneas notablemente bien dispuestas, por más que la primera muestre una cierta inclinación hacia abajo a partir de su mitad y la tercera un cierto decrecimiento de sus signos. Las letras son capitales — véase más abajo el estudio paleográfico-, con un módulo medio de de $7 \mathrm{~cm}$. Todas ellas han sido grabadas mediante una incisión de buena calidad, están provistas de remates y al final de la línea $3-y$, probablemente, también de la 1 , se han grabado signos de puntuación ornamentales-.

Los principales problemas de lectura se producen en las partes dañadas de la superficie de escritura. En la 1.1 se ha perdido el comienzo, en una extensión que permitiría el grabado de dos o tres letras; la primera letra visible, aunque incompleta, es una $\mathrm{E}$ y a partir de ahí todo es perfectamente legible con la

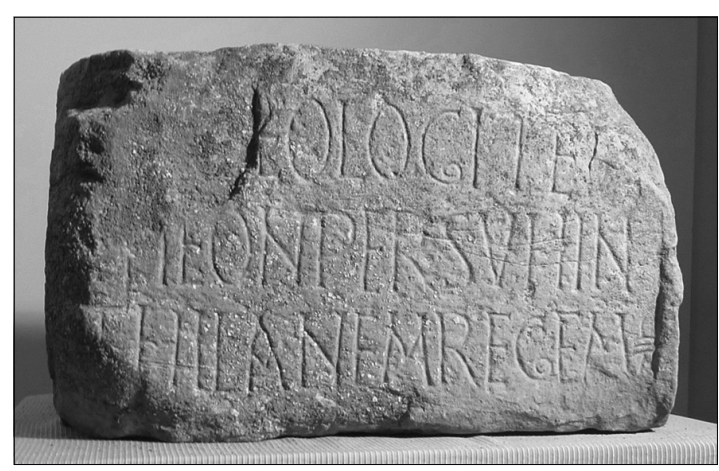

Figura. 2 Inscripción de Sansomain.

excepción del último signo. De él se conserva un trazo diagonal y ligeramente curvado hacia arriba, cruzado hacia su mitad por otro trazo de forma también semicurvada. Dadas las características de la escritura capital empleada, los restos del trazo no pueden coincidir con ningún otro signo alfabético, de modo que es verosímil que se trate de un signo de puntuación más o menos similar al que cierra la línea 3 . En la línea 2 se ha perdido también el inicio, en un número de signos que podría oscilar entre uno y dos. Lo primero que se percibe es un mínimo resto del pie de un trazo vertical, después la mitad inferior de otro trazo vertical y finalmente las tres cuartas partes inferiores de un tercer trazo vertical. Es muy difícil determinar si los dos últimos trazos descritos componen una única letra - tal vez una $\mathrm{N}$-, porque, como se verá más adelante, tampoco el sentido de la secuencia ayuda a la restitución. Por fin, en línea 3 solo los dos primeros signos se han visto afectados en su parte inferior por el desgaste de la piedra, pero en esta ocasión el contexto permite confirmar su lectura sin mayores problemas. De esta manera la lectura que puede proponerse para la inscripción es la siguiente:

\section{[-c. 2/3-]EOLOGITE . +++ EON PER SVHIN- THILANEM REGEM •}

Los problemas que el texto plantea son de orden diferente pero, a nuestro modo de ver, todos confluyen dos cuestiones nucleares: la de la datación de la pieza y la de su auténtico valor como testimonio histórico. Sin intentar agotar en este trabajo la riqueza del debate que la pieza sin duda suscitará, intentaremos plantear a continuación los elementos que entendemos como sustanciales para aproximarnos a su interpretación. 


\section{LA PALEOGRAFÍA}

Como se ha dicho, la inscripción ha sido grabada en letras capitales de muy buena factura. Las formas de algunos signos son comunes a muchos alfabetos capitales y apenas si nos pueden dar alguna información cronológica: así sucede, por ejemplo, con la I, la L, la O, la T, la R, la V, la S, la E, o la $\mathrm{P}$ -aunque en este caso el óculo cierra hacia la mitad del asta vertical, un rasgo evidentemente tardío-. Otros signos, sin embargo, muestran formas más significativas, que pueden contribuir a una aproximación más ajustada a la datación de la pieza:

A: La A consta de dos trazos oblicuos sobre cuyo vértice se ha marcado un remate. El habitual trazo transversal se ha sustituido por dos trazos en forma de V.

M: Los trazos exteriores de $\mathrm{M}$ no son paralelos entre sí, sino que se abren hacia abajo. Los trazos interiores no parten del extremo superior de los exteriores, sino de un punto situado aproximadamente en su cuarta parte superior (de modo similar al de $\mathrm{N}$ ).

$\mathrm{N}$ : El trazo interior no une los extremos de los exteriores, sino dos puntos situados aproximadamente en su cuarta parte.

G: La parte final de la letra adquiere una forma espiral o de caracol hacia el interior.

$\mathrm{H}$ : El trazo interior no es recto, sino que adquiere una forma de $\mathrm{V}$ muy abierta o, por decirlo así, de ave.

Las formas de las letras A y $\mathrm{N}$ tienen buenos paralelos desde las inscripciones del siglo III (Hübner 1885: 54-58); también en inscripciones de época imperial pueden hallarse formas de G acaracoladas; algo más tardía, ya de época visigoda, es la forma de la M. Pero todas ellas tienen una larga pervivencia, que se extiende en epígrafes hispanos hasta el siglo XII. Si se comparan, por ejemplo, con el repertorio establecido por De Santiago para las inscripciones de los condados catalanes, puede constatarse que las formas de A, de $\mathrm{G}$, de $\mathrm{M}$ y de $\mathrm{N}$ que se documentan en nuestra inscripción están perfectamente activas en el siglo XII (De Santiago 2003: 88, 94, 99 y 100); por lo que se refiere a $\mathrm{H}$, no hemos encontrado por el momento una forma idéntica, pero no es menos cierto que para encontrar ejemplos de $\mathrm{H}$ en los que la línea transversal no sea recta hay que descender también al siglo xII: obsérvense, por ejemplo, los casos catalanes catalogados por De Santiago en los que la forma de la línea central es similar a la que aquí se presenta, aunque con el vértice apuntando hacia arriba (De Santiago 2003: 95). En resumidas cuentas, la paleografía del epígrafe no es un elemento concluyente para determinar su datación, pero al mismo tiempo es cierto que no se opondría a una fecha tardía de la misma, en torno al siglo XII, momento al que, como se verá luego, apuntan también otros indicios.

Mención aparte merecen las dos interpunciones que se advierten en el texto. La primera, al final de 1. 1 , no se puede ver completamente a causa de la erosión de la piedra en ese punto, pero probablemente tenía una forma semejante a la segunda, la que aparece al final absoluto del texto. En este caso se trata de un trazo curvilíneo en forma de $\mathrm{S}$ alargada que es cruzada en su parte central por tres trazos cortos y ligeramente curvados (Fig. 3). No conocemos paralelos epigráficos para tal elemento de puntuación ornamental, pero sí que existen formas similares en

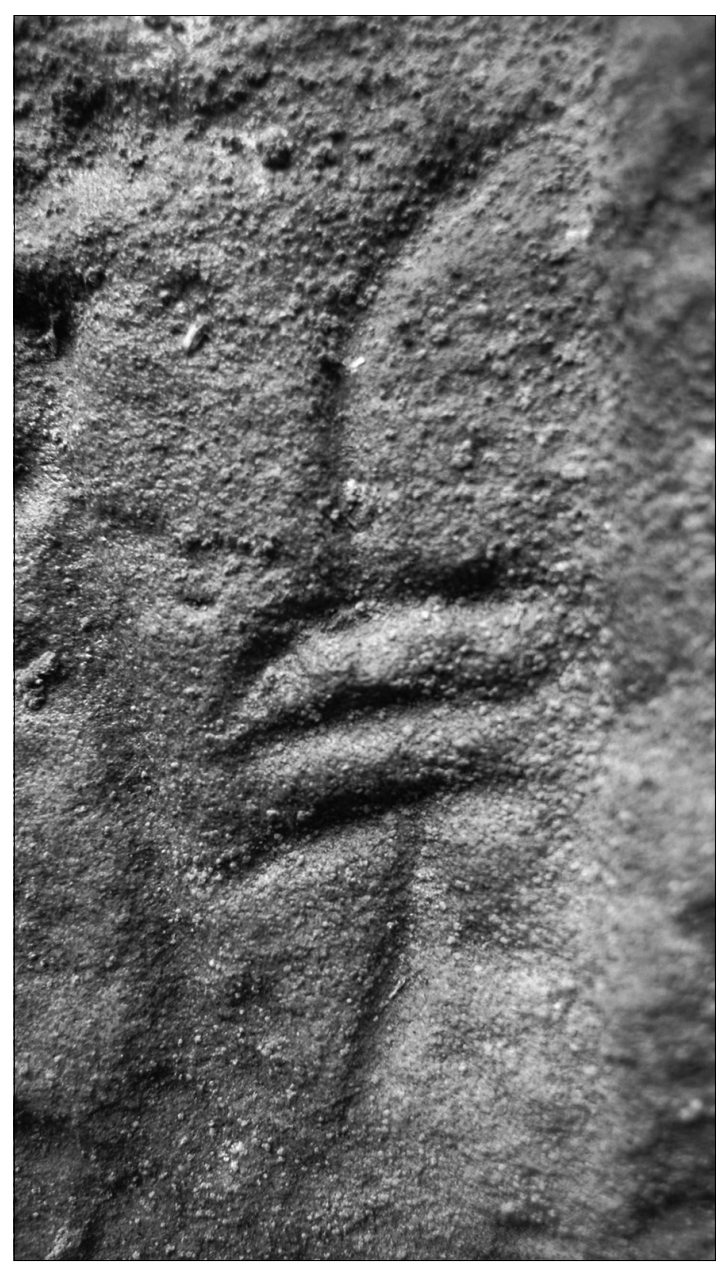

Figura. 3 Detalle de la interpunción de 1. 3. 
manuscritos datables a partir del siglo $\mathrm{x}$, lo que, como se verá, puede constituir también un indicio significativo en la interpretación del epígrafe.

\section{EL TEXTO}

Por lo que se refiere al texto, desde un primer acercamiento resulta evidente su relación con un pasaje muy conocido de la Historia Gothorum de Isidoro de Sevilla:

"Isid. Historia Goth. 63:

Habuit quoque et initio regni expeditionem contra incursus Vasconum Tarraconensem provinciam infestantium, ubi adeo montivagi populi terrore adventus eius perculsi sunt, ut confestim, quasi debita iura noscentes, remissis telis et expeditis ad precem manibus, supplices ei colla submitterent, obsides darent, Ologitin civitatem Gothorum stipendiis suis et laboribus conderent, pollicentes eius regno ditionique parere, et quidquid imperaretur efficere".

El texto isidoriano, citado aquí según la edición de Mommsen (Mommsen 1894), menciona un episodio largamente tratado por la historiografía, según el cual el rey Suintila habría sometido a los Vascones y éstos, entre otras muestras de sumisión, habrían fundado, como ciudad de godos, ${ }^{2}$ la que se menciona como Ologitin. El pasaje se constituyó luego en fuente directísima de la historiografía medieval, en la que pronto se suscitó el debate sobre la identificación exacta del lugar al que correspondería Ologitin. Así, por ejemplo, Rodrigo Ximénez de Rada, en su Historia de rebus Hispaniae escrita en 1243, recrea el episodio, reproduciendo prácticamente las palabras de Isiodoro, pero incluyendo una mención al debate sobre la identificación del lugar:

"Rodericus Ximenius de Rada, Historia de rebus Hispanie siue Historia Gothica 2, 18, 1:

(...) In inicio regni incursus Vasconum coarthauit qui Terrachonensem prouinciam infestabant, ubi montiuag populi aduentus eius terrore perculsi, confestim quasi debita iura noscentes, remissis telis et complosis ad precem manibus, supplices submitterent ei colla; Ologitis ciuitatem Gothorum stipendiis suis et laboribus, ut eis parceret, fabricarunt [hanc quidam dicunt Olorum, quidam Olitum] pollicentes iurisditioni parere et imperio obedire".

Como dice el arzobispo toletano, algunos consideraban ya por su época que Ologitin debía de corresponder a Oloron, mientras que otros preferían situarla en la navarra Olite. La polémica, en realidad, era injustificada en lo que se refiere a Oloron: por un

\footnotetext{
${ }^{2}$ Sobre la interpretación del sintagma civitatem Gothorum véase lo que dijimos en Velaza 1997-98: 236. Sobre el pasaje, véanse, entre otros, Sayas 1987, Arce 2009, Moreno 2009 y Jimeno 2009.
}

lado, parece evidente que su situación no permite explicar la actuación de Suintila contra los Vascones; pero, por otro, hoy sabemos bien que el nombre antiguo de Oloron era Iluro, como nos documenta un miliario con el epígrafe Iluro(ne) m(illia) p(assuum) (CIL XVII.2 311 = CIL XIII 8894 (AE 1983, 691), de Urdos), además de otras fuentes (Raymond 1868: 124). No obstante, el debate tuvo un largo recorrido: así, por ejemplo, la Estoria General lo planteará en términos muy semejantes:

"E este fue el primero rey que a pesar de los romanos ouo quietamientre el regno de Espanna, et echo fuera del regno quantos romanos y allo, lidiando con ellos. E luego que el començo a regnar, corrien los gascones la prouincia de Tarragona, et fazien y grandes dannos. E el salió con su hueste a las montannas por o ellos uinien, et fizo en ellos grand astragamiento, de guisa que los torno a su uasallage; e por tal que los perdonasse, labraron le una cibdad de sus aueres. Vnos dizen que fue esta cibdad Oloron otros que Vlit".

Y todavía en el s. XVII el padre Moret se ve obligado a argumentar de este modo (Moret 1684):

“(...) Luego se le rindieron, y ofrecieron serle fieles, y admitieron la condición de fabricar a su costa y trabajo una población llamada Ologito para que fuese plaza de armas de los Godos contra sus correrías. El Arçobispo D. Rodrigo, que refiere esto como de S. Isidoro, y también D. Lucas de Tuyd, aunque nosotros no lo hallamos en él con toda seguridad, pone en duda si este pueblo Ologito es la Ciudad de Olite en Navarra o la de Oleron en Francia: Vaseo si Valladolid en Castilla. Esta caía muy lexos para el intento de los Godos; y Oleron, passado gran trecho el Pyreneo muy dentro de el señorio de los Francos y a grande distancia de los Godos. Olite por la situación muy a su intento era, entre el Ebro y Pyreneo y a donde feneciendo sus cumbres, y ramas, comiença ya a abrirse la tierra, y dilatarse en llanuras".

Pero, más allá de la discusión historiográfica, lo cierto es que la misma forma del topónimo es profundamente problemática. La forma Ologitin, consagrada como hemos visto por Mommsen en su edición, es solo una de las múltiples que se documentan en los manuscritos de Isidoro, como se encargó de anotar Arévalo en el aparato crítico: "In his nominibus propriis multum variant Codices". En efecto, conocemos variantes como Ologitis, Ologicus, Ologiciis, Ologitum, Theologitin, Theologite, entre las que los diferentes editores han optado de manera diversa: así, por ejemplo, Flórez mantuvo Ologitin (Flórez 1751:503, año 621), mientras que Grosse prefirió Ologicum u Ologicus (Grosse 1947: 255) y por esta última se decantó también el más reciente editor de la obra hasta el momento, Rodríguez Alonso.

No entraremos aquí en el espinoso asunto de cuál era en realidad la forma antigua del topónimo; en la compleja tradición textual de la Historia Gothorum, 
magníficamente delineada por Isabel Velázquez (Velázquez 2008), ese es solo uno más de los aspectos problemáticos. ${ }^{3}$ A decir verdad, entre las variantes Ologicus/Ologiciis y Ologitis/Ologitin resulta difícil escoger, porque cualquiera de las dos "familias" podría haberse generado a partir de la otra. Es mucho más evidente, sin embargo, que la tercera rama, la representada por Theologitin/Thologite no puede considerarse como auténtica, sino como una variante generada por una mala comprensión del topónimo y una corrección de algún copista acostumbrado al léxico teológico. Lo que nos interesa mucho más es señalar la posibilidad de que en la inscripción que nos ocupa la forma que se empleara fuese justamente la última de las mencionadas, esto es, Theologite. En efecto, a juzgar por el módulo medio de las letras, en la parte perdida de línea 1 quedaría espacio aproximadamente para dos letras, además de para completar la E que aparece rota en su comienzo. Parece, pues, verosímil, que en 1.1 solo apareciese la palabra THEOLOGITE ${ }^{4}$ lo que vendría también apoyado por el punto ornamental que cierra la línea. Si fuera así, estaríamos ante la prueba de que quien redactó el texto conocía el texto de Isidoro a través de un manuscrito que contenía tal variante, lo que parece llevarnos también a finales del siglo XI o al siglo XII.

Por lo que respecta al resto del texto, el principal problema reside en la comprensión de la secuencia inicial de 1. 2. Como ya se ha señalado, delante de las letras EON hay espacio para 2 o 3 más, pero los restos que se perciben no permiten una restitución verosímil. A ello se suma el hecho de que EON es un final imposible para una palabra latina; podría pensarse, por ejemplo, en NEON, pero a la difícil justificación de un helenismo en este contexto y cronología se añade el problema de que parece haber restos de un signo por delante; otras soluciones podrían pasar por suponer la existencia de una secuencia de abreviaturas, del tipo [I]N EO N(omine), pero lo cierto es que ninguna de las posibilidades se nos antoja plenamente satisfactoria y, por el momento, este extremo ha de quedar en cuarentena. ${ }^{5}$

Merece también un comentario la expresión per Suhinthilanem regem, construcción de per + acusa-

\footnotetext{
${ }^{3}$ Tampoco abordaremos aquí otro aspecto, por lo demás muy interesante, que es el de la etimología del topónimo. A pesar de que algunos trabajos recientes han establecido hipótesis de diversos tipos ( $c f$. Caro Baroja 1995, p. 989; Villar Prósper 2005, pp. 467-468), creemos que la cuestión permanece abierta.

${ }^{4}$ Quizás precedida también por otro punto ornamental.

${ }^{5}$ La hipótesis de las abreviaturas no se ve, por lo demás, apoyada por el resto del texto, donde todas las palabras aparecen escritas in extenso.
}

tivo que, si bien no comprendemos completamente el contexto, parece funcionar como agente, lo que nos daría también una datación tardía para la sintaxis. La forma Suhinthilanem - por Suinthilanem - es un hápax ortográfico, puesto que las formas más habituales de escribir el nombre del rey son Suintila o Suinthila, ambas presentes en la amonedación de la época $^{6}$ y la última en la forma de la desaparecida corona de Guarrazar (Velázquez 2001 y Molina Gómez 2004). La presencia de una segunda $H$ puede interpretarse como un error involuntario del redactor o del lapicida, pero también, quizás más verosímilmente, como un hipercultismo.

En resumidas cuentas, la nueva inscripción que aquí presentamos representa sin duda un documento de extraordinario interés y, a no dudarlo, propiciará debates en el futuro. Sin ánimo de zanjar ninguno de ellos, a nuestro modo de ver hay argumentos suficientes como para proponer para ella una datación en torno al siglo XII, un momento importante en la historia de Olite con la concesión del Fuero de Estella en 1147 por parte del rey García Ramírez y, en consecuencia, contexto muy adecuado para la grabación del epígrafe como forma de enaltecer el pasado local y una dependencia directa del texto de Isidoro, de cuya información no se constituye, pues, en elemento de confirmación, sino en nuevo testimonio de la vitalidad de su obra en época medieval. ${ }^{7}$

\section{BIBLIOGRAFÍA}

Arce, J. 2009: "Vascones y visigodos", J. Andreu (ed.), Los Vascones de las fuentes antiguas: en torno a una etnia de la antigüedad peninsular, Barcelona, 243-251.

Caro Baroja, J. 1995: “Observaciones sobre el vascuence y el Fuero General de Navarra”, Príncipe de Viana 206, 977-1002.

Díaz y Díaz, M. C. 1961: "Isidoro en la Edad Media hispana", Isidoriana, León 1961, 345-387 (= De Isidoro al siglo XI, Barcelona 1976, 141-201).

González Alonso, C. 1975: Las Historias de los Godos, Vándalos y Suevos de Isidoro de Sevilla, León.

Flórez, E. 1751: España Sagrada. VI, Madrid.

Grosse, R. 1947: Fontes Hispaniae Antiquae, 9. Las fuentes de época visigoda y bizantinas, Barcelona.

\footnotetext{
${ }^{6}$ Véase http://www.maravedis.net/visigodos_suinthila. html.

${ }^{7}$ Sobre la circulación de la obra de Isidoro en la Edad Media hispana sigue siendo fundamental Díaz y Díaz 1961 y 1976.
} 
Hübner, E. 1885: Exempla scripturae epigraphicae Latinae, Berlín.

Jimeno, R. 2009: "Vascones y visigodos: análisis iushistórico de la organización militar", J. Andreu (ed.), Los Vascones de las fuentes antiguas: en torno a una etnia de la antigüedad peninsular, Barcelona, 253-260.

Mommsen, Th. 1894: Sancti Isidori Hispalensis episcopi Historia de regibus Gothorum, Wandalorum et Suevorum, MGH AA 11, Chron. Min. II, Berlin.

Molina Gómez, J. A. 2004: "Las coronas de donación regia del tesoro de Guarrazar: la religiosidad en la monarquía visigoda y el uso de modelos bizantinos", Antigüedad y Cristianismo 21, 459-472.

Moreno Resano, E. 2009: "Los Vascones en la Literatura Latina tardía (siglos IV-VII)", J. Andreu (ed.), Los Vascones de las fuentes antiguas: en torno a una etnia de la antigüedad peninsular, Barcelona, 261-289.

Moret, J. de 1684: Annales del Reyno de Navarra, Pamplona.
Raymond, P. 1868: Dictionnaire topographique du Département des Basses-Pyrénées, Paris.

Sayas, J. J. 1987: "La actitud de los vascones frente al poder en época visigoda", Memorias Historia Antigua 8, 289-310.

Santiago Fernández, J. de 2003: La Epigrafía latina medieval en los Condados Catalanes (815 - circ. 1150), Madrid.

Velaza, J. 1997-98: “Olite romano: evidencias epigráficas", Trabajos Arqueología Navarra 13, 235 246.

Velázquez, I. 2001: "Las inscripciones del tesoro de Guarrazar”, A. Perea (ed.), El Tesoro visigodo de Guarrazar, Madrid, 321-346.

Velázquez, I. 2008: "La doble redacción de la Historia Gothorum de Isidoro de Sevilla”, M. ${ }^{\mathrm{a}}$ A. Andrés Sanz, J. Elfasi y J. C. Martín (eds.), L'edition critique des ouvres d'Isidore de Séville. Les recensions multiples, Paris, 91-126.

Villar, F. y Prósper, B. 2005: Vascos, celtas e indoeuropeos: genes y lenguas, Salamanca.

Recibido: 28-05-2011

Aceptado: 20-09-2011 